\title{
Microstructure and Properties of WC/diamond/Co- based Gradient Composite Coatings on High-speed Steel Fabricated by Laser Cladding
}

Donggang Liu

Taiyuan University of Technology

Guoxing Liang ( $\sim$ liangguoxing@tyut.edu.cn )

Taiyuan University of Technology https://orcid.org/0000-0003-2665-2341

Xinhui Hao

Taiyuan University of Technology

Yonggui Huang

Taiyuan University of Technology

Guang Li

Taiyuan University of Technology

Zheng Lv

Taiyuan University of Technology

Ming Lv

Taiyuan University of Technology

Mohammed Al-Nehari

Taiyuan University of Technology

Ojiako Tochukwu Princewill

Taiyuan University of Technology

\section{Research Article}

Keywords: Laser cladding, Gradient composite coatings, Microstructure, Wear resistance, Corrosion resistance

Posted Date: June 25th, 2021

DOI: https://doi.org/10.21203/rs.3.rs-638436/v1

License: (c) (i) This work is licensed under a Creative Commons Attribution 4.0 International License.

Read Full License 


\section{Abstract}

Improving the wear resistance and corrosion resistance of high-speed steel (HSS), WC/diamond/Cobased gradient composite coatings were produced on HSS substrates by laser cladding with different compositions powder mixture (Co-Cr alloy powder, 80Co-Cr alloy powder+20WC, 53Co-Cr alloy powder+40WC+7diamond, wt.\%). The macromorphology, microstructures and phase composition were characterized by optical microscope (OM), scanning electron microscopy (SEM) equipped with energy dispersion spectrometry (EDS), and X-ray diffraction (XRD) techniques. The microhardness, wear resistance and corrosion resistance of the gradient coatings were also investigated respectively. The results indicate that the prepared WC/diamond/Co-based gradient composite cladding layer has a fine morphology on the cross sections and a gradient transition of the grain size has been achieved. The microhardness result presents gradient distribution along the depth of the coating. The microhardness is strengthened due to the dispersions of $\mathrm{M}_{7} \mathrm{C}_{3}\left(\mathrm{M}\right.$ is $\mathrm{Fe}, \mathrm{Cr}$ ), $\mathrm{Co}_{3} \mathrm{C}, \mathrm{CrCo}, \mathrm{Cr}_{3} \mathrm{C}_{2}, \mathrm{Fe}_{3} \mathrm{C}$ in the composite coating, and the highest microhardness of $1342 \mathrm{HV}_{0.2}$ can be detected in the cladding layer. The friction coefficient values of the coatings range from 0.27 to 0.40 , which is much lower than that of the substrate (0.50-0.60). Furthermore, the wear loss of coatings decreases by more than 3 times comparing with that of the substrate $(3.5 \mathrm{mg})$. The polarization resistance results show that the cladding layer has excellent corrosion resistance with polarization resistance can reach the value of $236488.1 \Omega \cdot \mathrm{cm}^{2}$. The gradient transition of the mechanical properties and chemical metallurgical combination between particle (WC,

diamond) and adhesive phase can be obtained in laser cladding, which improves the wear resistance and corrosion resistance of the HSS surface.

\section{Introduction}

Presently High-speed steel(HSS) is widely used in the manufacturing of various cutting and forming tools, owing to its outstanding physical properties such as high hardness, high wear resistance and high heat resistance. HSS accounts for more than $30 \%$ of the global tool market [1, 2]. However, serious wear and corrosion have been frequently triggered as a result of the friction during a cutting process and the service life of the tools cannot meet the requirements of the engineering applications. Therefore, a few appropriate surface-modified techniques have been conducted to optimize and innovate HSS tools such as physical vapor deposition (PVD), chemical vapor deposition (CVD), plasma spraying and laser cladding [3-6]. As far as these surface-modified techniques, laser cladding technique has the advantage of rapid melting and solidification, little thermal deformation, low coating dilution rate, the wide selection of cladding materials, convenient operation, economical and practical advantages, etc. Moreover, the metallurgical bond between the coating material and substrate is more likely to be realized depending on the laser cladding coating technique. Consequently, the laser cladding technique is a suitable process to improve the performance of the tool [7-9].

Generally, Metal materials together with the additives of the high hardness phases (such as WC, diamond, $\mathrm{TiC}$, etc.) could realize the admirable toughness, thermal conductivity as well as wear resistance and heat corrosion. The perfect properties could be obtained by combining these kinds of materials in the clad 
layers [10-12]. Nevertheless, the bonded performance on the interface between the clad layer and the substrate of HSS became weak, the cracks and the cavities had been produced in the laser cladding process. Such flaws spotted in the cladding layer mainly are attributed to two aspects, one is the characteristics of the rapid melting and solidification in the laser cladding process and the other is the difference in the thermal properties between the substrate and the composite material. The different proportion from the substrate surface to the clad surface is as a result of the stepwise added ceramics, the functional gradient coating layer could be created and the smooth transition between the layer and matrix could be produced, which can provide a solution to reduce or eliminate the problem of poor interface bonding. On that note, the efficient connection of different materials will be achieved $[13,14]$.

Presently, investigation on functionally graded coatings is mainly carried out in the aspects of material component design, cladding layer performance, and process parameter optimization. Liang et al. [15] Prepared $\mathrm{TiC}$ and $\mathrm{TiB}_{\mathrm{X}}$ reinforced $\mathrm{TiNi} / \mathrm{Ti}_{2} \mathrm{Ni}$ gradient composite coatings on $\mathrm{TC} 4$ substrate by laser cladding with different composition powder mixture $\left(10 \mathrm{~B}_{4} \mathrm{C}+90 \mathrm{TiNi}, 20 \mathrm{~B}_{4} \mathrm{C}+80 \mathrm{TiNi}, 30 \mathrm{~B}_{4} \mathrm{C}+70 \mathrm{TiNi}\right.$, wt.\%). The results showed that the microhardness of the coating is $1555.1 \mathrm{HV} 0.2$, which was 4.6 times that of the substrate $\left(340 \mathrm{HV}_{0.2}\right)$, and the wear mass loss of coatings had more than $50 \%$ reduction compared with that of the substrate $\left(3.2 \times 10^{-3} \mathrm{~g}\right)$. Liu et al. [16] fabricated a gradient Ni-Ti coating on the surface of the TA2 titanium alloy substrate by laser cladding. Studies have found that $\mathrm{NiTi}, \mathrm{NiTi}_{2}$ and $\mathrm{Ni}_{3} \mathrm{Ti}$ intermetallic compounds in the coating significantly improved the microhardness and oxidation resistance. Wang et al. [17] successfully prepared the nano-TiC functional gradient wear-resistant composite coating on $40 \mathrm{Cr}$ gear steel by laser cladding under starved lubrication conditions. The results showed that the TiC was transformed from nanoceramic particles embedded in the coating interior to an agglomerated large-volume hard phase structure as the pre-prepared nano-TiC powder increased, the micro-hardness gradually increased from $612 \mathrm{HV}$ at the bottom of the gradient coating to $1088 \mathrm{HV}$ at the top. Compared with uniform coating, the gradient coating showed a $50 \%$ reduction in friction coefficient, a $40 \%$ reduction in grinding loss, and a significant increase in wear resistance under heavy load and starved lubricant conditions. Bartkowski et al. $[18,19]$ investigated the influence of laser remelting on the microhardness and corrosion resistance of the cladding layer prepared with Stellite-6/WC. Their research found that with the increase of WC content, the microhardness of the coating increased while the corrosion resistance decreased. Shi et al. [20] used Co50 and Ni/WC mixed powder to prepare a gradient cladding layer onto $20 \mathrm{CrMnTi}$ low carbon alloy steel, and optimized the laser process parameters by Taguchi OA and TOPSIS method. This optimized coating not only had three times microhardness compared with the substrate but also increased the wear resistance to 36.4 times. Riabkina-Fishman et al. [21] prepared a multi-layer cladding layer of functionally graded carbide alloy on the surface of M2 high-speed steel by directly injecting WC powder into the melt pool, and found that many cracks were generated at the bonding interface between the cladding layer and the substrate. Fomin et al. [22] reported that the distribution of WC was close to the matrix in the laser cladding metal wear resistant coating. However, there are few studies on the influence of WC/diamond/Co-based gradient composite cladding layer on the comprehensive performance of HSS. 
In this research, the different compositions powder mixture of WC/diamond/Co-based gradient composite coatings were produced on HSS substrate by laser cladding. The microhardness, wear resistance and electrochemical properties of the coatings with different compositions were investigated. The complex analysis of the gradient composite, including the crystallographic relationships between compositions could be helpful for a better understanding of the alloying process of the involved materials in the cladding layer.

\section{Materials And Methods 2.1 Materials}

The substrate was HSS alloy tool steel (Yongxing Special Steel Tools Co. Ltd., Dongtai, China) with a size of $60 \times 30 \times 6 \mathrm{~mm}^{3}$. And its compositions are listed in Table 1. The oxide layer of HSS was polished and removed by the grinding machine (YMP-2B, Shanghai Puda Optical Instrument Co. Ltd., Shanghai, China). Each specimen was dipped in an ultrasonic cleaner (FRQ-1008HT, Hangzhou Farant Ultrasonic Technology Co. Ltd., Hangzhou, China) with anhydrous ethanol and acetone before laser cladding. Spherical Co-Cr alloy powder (Shenyang Rare Metal Research Institute, Shenyang, China, $-100+300$ mesh, XYFCo6Z type), spherical cast tungsten carbide powder (Tianjiu Metal Materials Co., Ltd., Changsha, China, $-100+300$ mesh), synthetic diamond abrasive (Henan Huanghe Whirlwind Co., Ltd., Henan, China, $-100+120$ mesh, HFD-C type) were selected as the cladding materials for the subsequent experiments. The micrograph of powders are shown in Fig. 1, and the chemical compositions of spherical Co-Cr alloy powder are given in Table 2.

Three powders were mixed in a stainless steel jar on an all-around planetary ball mill machine (QM-QX04, Nanjing Nanda Instrument Plant, Nanjing, China) for 4 hours respectively. The ball-to-powder weight ratio of 5:1 was maintained throughout the milling time. After mixing mechanically, it was dried for 24 hours in a vacuum drying oven. The gradient composite coating is designed with a preliminary optimized multilayer structure. From the bottom layer to the top layer, the compositions are Co-Cr alloy powder (First layer, wt.\%), 80Co-Cr alloy powder + 20WC (Second layer, wt.\%), and 53Co-Cr alloy powder + 40WC + 7diamond (Third layer, wt.\%), respectively.

Table 1

Chemical compositions of high-speed steel (wt.\%).

\begin{tabular}{|lllllllll|}
\hline Material & W & Cr & V & C & Mn & Si & Mo & Fe \\
\hline High-speed steel & $17.5-19.0$ & $3.8-4.4$ & $1.0-1.4$ & $0.7-0.8$ & $0.1-0.4$ & $0.2-0.4$ & $\leq 0.3$ & Bal. \\
\hline
\end{tabular}

Table 2

Chemical compositions of Co-based alloy (wt.\%).

\begin{tabular}{|llllllllll|}
\hline Material & C & Cr & W & Si & Mn & Fe & Ni & Mo & Co \\
\hline Co-based alloy & 1.17 & 29.53 & 4.97 & 1.26 & 0.21 & 2.43 & 2.02 & 0.34 & Bal. \\
\hline
\end{tabular}




\subsection{Experimental methods}

The schematic diagram of the laser cladding process as well as the structure of the cladding layer is shown in Fig. 2. The laser cladding test was carried out on HWL-S1000W semiconductor laser cladding equipment (Dongguan Huawei Laser Equipment Co. Ltd., Dongguan, China). The laser generator is the fundamental transverse mode TEM00, the maximum output power is $1 \mathrm{~kW}$, and the wavelength is 980 $\mathrm{nm}$. The laser cladding head is composed of three coaxial powder feeding nozzles which are distributed around a circumferential direction with a spacing angle of $120^{\circ}$. The coaxial powder feeding scheme was applied in the experiments. Argon gas was selected to convey the powder and protect the molten pool from oxidation during the laser cladding process. Simultaneously, argon gas with an airflow rate of 15 $\mathrm{L} / \mathrm{min}$ to avoid the lens being burned by splashed powder. The powder flows from three nozzles collect at the focus. Intersection angle with an $85^{\circ}$ between the nozzle axis and the surface of the specimen is determined. The parameters to clad each layer are listed in Table 3.

Table 3

The laser cladding parameters of each layer

\begin{tabular}{|lllll|}
\hline $\begin{array}{l}\text { Cladding } \\
\text { layer }\end{array}$ & $\begin{array}{l}\text { Power } \\
(\mathrm{kW})\end{array}$ & $\begin{array}{l}\text { Scanning speed } \\
(\mathrm{mm} / \mathrm{min})\end{array}$ & $\begin{array}{l}\text { Powder feeding rate } \\
(\mathbf{g} / \mathbf{m i n})\end{array}$ & $\begin{array}{l}\text { Overlap } \\
\text { rate }\end{array}$ \\
\hline First layer & 7.5 & 120 & 32 & $25 \%$ \\
\hline Second layer & 7.0 & 120 & 32 & $22 \%$ \\
\hline Third layer & 7.0 & 300 & 32 & $20 \%$ \\
\hline
\end{tabular}

After the laser cladding process, the cross-section of clad specimens was prepared by using an electrical discharge wire cutting machine for analyzing the microstructure. The samples were ground by using emery paper with grain sizes from 240 to 1600 and polished by the diamond grain with a particle size of $1.5 \mu \mathrm{m}$. Before observing the microstructure of the cladding layer, the samples were etched with $\mathrm{HCl}$ and $\mathrm{HNO}_{3}$ solutions at 3:1 to reveal the microstructure of the cladding layer. The microstructures and compositions of gradient composite coatings were researched using a VEGA 3 SBH scanning electron microscopy (SEM) equipped with an Oxford X-ray energy dispersion spectrometry (EDS). A TD 3600 X-ray diffractometer (XRD) with Cu-K radiation $(k=0.154 \mathrm{~nm})$ was used to identify the phases in the cladding surface. Employed a diamond pyramid indenter under a load of $1.961 \mathrm{~N}$ for $15 \mathrm{~s}$, Vickers hardness of the polished surface was measured on HMV-G21ST microhardness tester. Along the clad surface of the HSS substrate, the hardness was detected at an interval of $0.1 \mathrm{~mm}$. The hardness result was obtained from the mean value of three measurements tested at the same horizontal position. The tribological tests were carried out on a CFT-I multi-functional reciprocating tribotester (Zhong Ke Kai Hua Corporation, Lanzhou, China) with a ball-on-plate configuration, and the counterpart was an $\mathrm{Al}_{2} \mathrm{O}_{3}$ ball with a diameter of $4 \mathrm{~mm}$. The mean value of the sliding speed was $12 \mathrm{~m} / \mathrm{min}$, and the normal load was $100 \mathrm{~N}$. The testing time was $30 \mathrm{~min}$, and the sliding stroke was $5 \mathrm{~mm}$. All the tests were conducted at least three times to ensure repeatability. A FA2240 electronic analytical balance (accuracy $\pm 0.1 \mathrm{mg}$ ) was employed to measure the mass difference before and after the wear test. Potentiodynamic corrosion tests in $3.5 \% \mathrm{NaCl}$ solution 
were carried out using a CHI660E electrochemical working station (Shanghai Chenhua Instrument Co., Ltd., Shanghai, China). The specimens with an area of $35 \mathrm{~mm}^{2}$ were studied at room temperature (25 $\left.{ }^{\circ} \mathrm{C}\right)$. A standard three-electrode cell was used, and the sample was the working electrode, the acicular platinum electrode was the auxiliary electrode, and the saturated calomel electrode was involved as the reference electrode [23]. Potentiodynamic polarization experiment was performed with a $1 \mathrm{mV} / \mathrm{s}$ potential sweep rate, and the potential ranges from -1.2 to $0.2 \mathrm{~V}$ in the open circuit potential.

\section{Results And Discussion}

\subsection{Morphology of gradient cladding layer}

Figure 3 presents the surface and cross-section macro morphology of the gradient cladding layer. It can be observed in Fig. 3(a)-(c) that relatively smooth cladding layers were fabricated. Diamond abrasive has been tightly embedded in the top cladding layer (Fig. 3(c)). Different phases had been produced during the laser cladding process owing to the variety of contents in each layer. Therefore the boundary interfaces can be clearly distinguished on the section surface. Few pores and cracks have been induced (Fig. 3(d)-(e)). WC particles are diffused in the top of the second and third layers. Slightly graphitization occurred on the diamond particles at the high temperature in the cladding process, which leads to the dark color being shown on the top surface. After cladding the third layer, a few pores were produced in both the second and third layers (Fig. 3(f)). It arises from a little graphitization of the diamond. When the high-energy laser beam irradiates the diamond surface, carbon dioxide has not enough time to bubble to the surface of molten metal and the bubbles were coalesce in rapid solidification. Then a few pores were holden in the cladding layer.

\subsection{Metallography of gradient cladding layer}

In the process of laser cladding, the solidification of the cladding layer begins at the combination region of the cladding layer and substrate. The grain growth is affected by thermal convection in the molten pool, mutual restriction between the grains, supercooling of the crystalline located in the front, solute distribution, and other factors. The morphology of grain growth is diverse, which leads to the difference in the solidification structure of each region in the cladding layer. The crystalline morphology of the cladding layer mainly depends on the liquid phase compositions and shape control factor in the molten pool. The shape control factor can be described as the ratio of the temperature gradient $\mathrm{G}$ and the solidification speed $R$ in the crystallographic direction (G/R). Under the condition of relatively stable compositions, the ratio of $\mathrm{G} / \mathrm{R}$ determines the growth morphology of the solidified structure. At the initial stage of the solidification, the temperature gradient $\mathrm{G}$ at the bonding interface reaches the maximum, and the solidification rate $\mathrm{R}$ approaches 0 . The liquid nucleates at the interface and the solidification structure grow in a low-speed plane to form planar crystals [24]. With the advancement of the solidification front, the actual temperature gradient decreases and the solidification rate relatively increases, therefore the $\mathrm{G} / \mathrm{R}$ value decreases, and significant epitaxial occurred close to the cladding bottom. Columnar cell crystals and columnar dendrites begin to form as well. In the subsequent solidification process, the 
smaller temperature gradient together with the larger solidification rate on the top of the cladding layer will result in the growth rate of crystal grains being lower than that of the nucleation. This region happens to be where the fine grains tend to develop [25].

The microstructure of the bonding interface of each layer of the gradient cladding layer is shown in Fig. 4. Because the cladding layer contains multi-component, the phase composition of the composite coating does not present a single microstructure. In general, the microstructure at the bottom of the gradient cladding layer is more coarse than the cladding layer at the top. The microstructure of the cladding layer grows to a certain extent due to repeated heating.

Figure 4(a) shows the microstructure distribution of the interface between the HSS matrix and the first layer. Grains in the layer were preferentially formed at the edge of the micro-melton pool close to the rough substrate due to the asperous surface being regarded as the core of non-spontaneous nucleation. The grains, located in the first layer, grow into the melting zone in the shape of the cellular crystal, and the shape of the crystal appears to be a narrow band. Some coarse columnar dendrites were directly formed close to the interface between the substrate and the cladding layer. It is not enough for the cellular crystal to expand completely within a transitoriness due to rapid heating-cooling in the process of laser cladding. Therefore, the growth direction of a crystal was constrained in the direction of the temperature gradient, and its shape was constrained to be a narrow band. There was an abrupt temperature change at the interface between the coating bottom and substrate due to the instant heat conduction in the laser cladding. The rate of crystallization is relatively low in the melton pool and the region occupied by supercooled composition became narrow, which will give rise to cellular crystal migrating forward to the pool in the crystallization growth. With the solidification interface developing forward, the gradual transition from cellular crystal to the coarse columnar dendrite will provide a multi-component eutectic structure among dendrites. The columnar dendrites will grow perpendicular to the matrix surface due to the solute enriched along the growth direction of the cellular crystal due to the composition being supercooled. The smoother the temperature in a higher solidification is, the finer microstructure in the cladding layer will be. The growth direction of dendrites was constrained to a particular direction and multiple eutectic structures were produced among dendrites.

Figure 4(b) shows the microstructure of the interface between the first layer and the second layer. In the transition zone, the number of equiaxed grains increases obviously and few planar crystals can be found. Finer columnar dendrites in the second layer can be easily observed in comparison with that of the first layer, and its growth direction expands upward along the direction of columnar dendrites of the first layer to the second layer. Some of the dendrites present dislocation growth due to the Marangoni convection generated in the molten pool. Figure 4(c) presents the microstructure of the bonding interface between the second layer and the third layer. It can be found that grains located at the bonding interface are finer than that of the transition zone above mentioned. The cladding layer of third is composed of a white acicular dendrite, dark interdendritic eutectic structure as well as elliptical WC particles. It can be explained that the first layer evolved in the process of remelting, quenching, and tempering during the second layer was prepared. Grains located in the first layer were coarsened due to the reciprocal laser 
scanning and the temperature gradually increasing in the tempering zone. A few equiaxed dendrites continuously grew crossing over the interface between two coatings (In Fig. 4(b)), which is conducive to improving comprehensive performance for the cladding layer. Depending on the residual heat in the layer after cladding the first layer, a proper temperature was provided for grain refinement at the bonding interface between the two layers. Although the ratio of temperature gradient $\mathrm{G}$ to solidification rate $\mathrm{R}$ between the two layers is large, it is not enough for the plane crystals to be produced completely. With the following layers being fabricated, continuous epitaxial columnar dendritic crystals are formed in the remelted region, and the equiaxed dendrite in the non-remelted region is retained. Non-remelted equiaxed dendrite close to the interface between two layers would experience a quenching process and grains in this region were refined [26].

\subsection{Phase composition and microstructure of gradient cladding layer}

Figure 5 shows the XRD results of the gradient cladding layer of WC/Diamond/Co-based base alloy. By comparing the standard PDF card, the cladding layer is composed of $W C, M_{7} C_{3}(M$ is Fe, $C r), C_{3} C, W_{2} C$, CrCo, $\mathrm{Cr}_{3} \mathrm{C}_{2}, \mathrm{Co}, \mathrm{Fe}_{3} \mathrm{C}$, and $\mathrm{C}$. The diffraction peaks of basic phases such as $\mathrm{WC}$ and $\mathrm{W}_{2} \mathrm{C}$ are not obvious on the cladding surface owning to the larger density of cast WC sinking to the bottom of the molten pool. Existence phases of $\mathrm{M}_{7} \mathrm{C}_{3}$ (M is $\mathrm{Fe}, \mathrm{Cr}$ ), $\mathrm{Co}_{3} \mathrm{C}, \mathrm{CrCo}, \mathrm{Cr}_{3} \mathrm{C}_{2}$, and $\mathrm{Fe}_{3} \mathrm{C}$ indicate that cast $\mathrm{WC}$ and diamond experience the process of phase transformation during the laser cladding. Part of cast WC was decomposed into $\mathrm{W}, \mathrm{C}$ elements accompanied by graphitization phase transformation which diffuses into the Co-Cr alloy and $\mathrm{M}_{7} \mathrm{C}_{3}(\mathrm{M}$ is $\mathrm{Fe}, \mathrm{Cr}), \mathrm{Co}_{3} \mathrm{C}, \mathrm{CrCo}, \mathrm{Cr}_{3} \mathrm{C}_{2}, \mathrm{Fe}_{3} \mathrm{C}$ and other hard phases were formed in the process of solidification [18]. The performance of the cladding layer would be improved by the homogeneous distribution of the phase on the cladding surface.

Figure 6 shows the section microstructures of the gradient cladding layer. Figure 6(a) shows the micro enlarged view of columnar dendrites distributed in the first layer, which is composed of bright gray fine eutectic dendritic (marked with the number 2), dark gray columnar dendrite (marked with the number 1), and white spherical particles (marked with the number 3 ). Figure 6(b) displays the micromorphology close to WC particles in the third layer. WC particle performed as non-uniform nucleation of the initial point. At first, fine ring banded crystals were produced at the interface between WC and bond phase. As the solidification of the interface develops, the temperature gradient decreases whereas the solidification rate increases, which could result in the coarse dendrite (marked with the number 6) growing forward perpendicular to the ring interface around WC particles. The component supercooling was generated due to the solute enrichment in the front of the cellular crystal, coarse dendrites grow perpendicular to the interface [27].

Figure 6(c) shows the enlarged view of white fine needle crystal and lath crystal close to the bonding interface of the second layer and the third layer. It can be seen that the white crystal phase seems to be in a poor density. As a second phase, the equiaxed crystal (marked with the number 7 ) is distributed in the gray matrix structure (marked with the number 8). Figure $6(d)$ is a magnified view of the white-banded 
crystal located in the third layer. A fine network white crystal (marked with the number 10) together with gray stripe crystal (marked with the number 11 ) is equidistantly distributed in the band. Figure 6(e) shows the morphology of the upper and middle parts of the third layer, which comprises of gray lath crystal (marked with the number 12) and fine-grained bright white equiaxed crystal (marked with the number 13). Regular polygonal-like columnar grains exist in the microstructure close to the surface cladding layer and its morphology is presented in Fig. 6(f). It is consists of regularly arranged dark gray equiaxed dendrites (marked with the number 14) and bright gray solid solution (marked with the number 15).

d Net crystal of third layer. e Subsurface. f Surface

EDS analysis was conducted to identify the chemical compositions of each structure in the gradient cladding layer. The analysis results are listed in Table 4. It can be observed that fine dendrite 2 and columnar dendrite 1 are mostly made up of $\mathrm{W}, \mathrm{Cr}, \mathrm{Fe}$, and $\mathrm{Co}$. More contents of $\mathrm{W}$ and $\mathrm{Cr}$ in light gray dendrite can be detected than that in the dark gray columnar dendrite, which can be identified as cobaltrich compounds with $\mathrm{W}, \mathrm{Cr}$ and other elements in solid solution. Dendrite 6 grown on the surface of WC particle is mostly composed of three elements of $\mathrm{W}, \mathrm{Cr}$ and $\mathrm{Co}$, while $\mathrm{W}$ accounts for a large proportion. The composition of dendrite 6 is similar to that of equiaxed crystal 7, which can be identified as the precipitated phase after WC dissolution. The melting point of WC is as high as $2870{ }^{\circ} \mathrm{C}$, which is much higher than that of HSS. When the molten pool is cooled and solidified to room temperature at a certain speed, high melting point WC particles crystallize into the solid particle form as the temperature of the liquid metal decreases. Dispersed fine particles will restrain the dislocation movement and grain boundary migration, which could refine the grains and significantly improve the strength of the coating [28]. Higher content of Co content could be detected in the reticular structure 10, fine equiaxed grain 13 as well as equiaxed dendrite 15 , and the content of solid solution $\mathrm{W}$ and $\mathrm{Cr}$ is also high, which is the eutectic structure of solid solution $\mathrm{W}, \mathrm{Cr}$ and other elements. The high supercooling degree of the surface layer leading to the increase of the nucleation rate, the microstructure of the cladding layer is refined during the rapid solidification of laser cladding. 
Table 4

Chemical composition of typical structures of the laser cladding coating as shown in Fig. 6 (wt.\%)

\begin{tabular}{|lllllllllll|}
\hline Positions & $\mathbf{W}$ & $\mathbf{V}$ & $\mathbf{C r}$ & $\mathbf{S i}$ & $\mathbf{F e}$ & $\mathbf{C o}$ & $\mathbf{C}$ & $\mathbf{N i}$ & Mo & $\mathbf{0}$ \\
\hline 1 & 2.84 & 0.00 & 17.45 & 0.89 & 35.69 & 39.48 & 2.35 & 1.30 & 0.00 & 0.00 \\
\hline 2 & 4.99 & 0.14 & 25.27 & 0.77 & 29.33 & 30.19 & 7.09 & 0.99 & 1.22 & 0.00 \\
\hline 3 & 2.81 & 0.00 & 5.63 & 0.82 & 30.62 & 31.54 & 19.52 & 0.98 & 0.00 & 8.07 \\
\hline 4 & 23.80 & 0.24 & 22.85 & 0.01 & 3.12 & 43.56 & 4.80 & 1.63 & 0.00 & 0.00 \\
\hline 5 & 10.09 & 0.00 & 21.68 & 1.09 & 3.98 & 48.39 & 11.16 & 3.60 & 0.00 & 0.00 \\
\hline 6 & 48.34 & 0.71 & 16.36 & 0.00 & 3.06 & 28.27 & 2.95 & 0.30 & 0.00 & 0.00 \\
\hline 7 & 56.20 & 0.00 & 12.66 & 1.09 & 1.55 & 24.78 & 3.09 & 0.63 & 0.00 & 0.00 \\
\hline 8 & 17.15 & 0.08 & 27.01 & 0.12 & 4.43 & 40.58 & 9.01 & 1.62 & 0.00 & 0.00 \\
\hline 9 & 14.77 & 0.07 & 48.15 & 0.00 & 2.68 & 24.09 & 10.08 & 0.16 & 0.00 & 0.00 \\
\hline 10 & 33.01 & 0.00 & 12.66 & 0.96 & 2.65 & 49.03 & 1.52 & 0.17 & 0.00 & 0.00 \\
\hline 11 & 4.99 & 0.14 & 25.27 & 0.77 & 29.33 & 30.19 & 7.09 & 0.99 & 1.22 & 0.00 \\
\hline 12 & 28.76 & 0.97 & 12.89 & 0.09 & 2.78 & 47.49 & 5.98 & 1.04 & 0.00 & 0.00 \\
\hline 13 & 2.84 & 0.00 & 17.45 & 0.89 & 35.69 & 39.48 & 2.35 & 1.30 & 0.00 & 0.00 \\
\hline 14 & 16.27 & 0.00 & 38.69 & 0.00 & 3.04 & 28.28 & 13.49 & 0.24 & 0.00 & 0.00 \\
\hline 15 & 25.98 & 0.00 & 36.16 & 0.15 & 3.66 & 29.05 & 4.02 & 0.98 & 0.00 & 0.00 \\
\hline
\end{tabular}

\subsection{Element distribution in the bonding interface of gradient cladding layer}

Figure 7 presents the microstructure of the bonding interface and main element distribution in the gradient cladding layer. Figure 7(a) presents the bonding interface between the first layer and the HSS matrix. A light gray transition zone at the bonding interface can be observed. The element distributions were monitored along the arrow direction (marked with the yellow arrow) and the result is shown in Fig. $7\left(\mathrm{a}_{1}\right)$. Five main elements $(\mathrm{Fe}, \mathrm{Cr}, \mathrm{Co}, \mathrm{W}$ and $\mathrm{C})$ were detected in the bonding interface. The elementary transition was generated at the interface between the matrix and the cladding layer. Almost all elements at the interface are distributed in a gradient with $\mathrm{Co}$ and $\mathrm{Cr}$ are mostly distributed in the cladding layer, while Fe is mostly distributed in the HSS matrix. This gradient helps improve the compatibility of the HSS matrix and the cladding layer, which leads to smooth stress transfer and avoiding interface failure. In the cladding layer, an inclination of the conversion presentation occurs on the contents of elements $\mathrm{Cr}$, Fe, and $\mathrm{Co}$. The total content of three kinds of element is held constant. It is implied that a Co-based solid solution being rich in $\mathrm{Cr} / \mathrm{Fe}$ is produced in the cladding layer. Figure 7(b) shows the bonding interface between the second layer and the first layer. It can be observed that bright 
white dendrites are densely distributed at the bonding interface, with the dark gray columnar dendrites fine and dislocated. Comparing with the first layer, the bright white coarse dendrites can be easily found in the second layer. The element contents present smooth distribution in the cladding layer according to the EDS results, as shown in Fig. 7( $\left.b_{1}\right)$. The Fe element content of the first layer is more than that of the second layer. Figure 7(c) shows the bonding interface of the third layer and the second layer. A fine white transition zone observed at the bonding surface indicates that the compact fine equiaxed grains are produced after laser cladding. In Fig. 7( $\left.\mathrm{C}_{1}\right)$, four elements of W, C, Cr, and Co can be detected in the bonding interface. Each element concentration presents a smooth transition along the leader direction marked in Fig. 7(c). The opposite inclinations appear on element distributions of $\mathrm{Co}$ and $\mathrm{Cr}$ in the detection area. It is indicated that the solid solution of Co-based composition enriched with $\mathrm{Cr}$ is produced in the cladding layer. More element contents of $\mathrm{W}$ and $\mathrm{C}$ are monitored in the cladding layer due to the additive of WC particles in cladding material preparation. The content of W and $\mathrm{C}$ in the third layer is more than that in the second layer under the action of a high energy laser beam. In addition, the graphitization of diamond will dissolve into the cladding layer and increase the content of element $\mathrm{C}$. It can be seen in Fig. 7(d) that WC particles are closely combined with the binder phase. The bright thin ringlike interface is produced around each WC particle. Along the leader direction marked in Fig. 7(d), gradual transition distributions are tested on three elements of $\mathrm{W}, \mathrm{Cr}$, and $\mathrm{Co}$, as shown in Fig. $7\left(\mathrm{~d}_{1}\right)$. Elementary contents of W, Co, and $\mathrm{Cr}$ can be found at the interface. Close to the WC three elementary contents are kept at an intermediate level. Dendrite deposited near WC particle is helpful to the stability of the transition and the combined performance between particle and binder phase can be greatly improved. The elementary contents of $\mathrm{Co}$ and $\mathrm{Cr}$ present opposite distribution inclination in the dendrite and binder phase. It implies that a Co-based solid solution is produced in laser cladding. In Fig. 7(e), the diamond particle is compactly embedded in the cladding layer. Although ground and polished for a long time in the sample preparation, the diamond is tightly enclosed around the binder phase in the cladding layer. According to the detection results shown in Fig. $7\left(\mathrm{e}_{1}\right)$, the bonding interface composition contains mostly three elements of $\mathrm{C}, \mathrm{Cr}$, and $\mathrm{Co}$. Each element distribution close to the diamond abrasive presents a gradient transition along the leader marked in Fig. 7(e). There is a little amount of Co and $\mathrm{Cr}$ elements can be detected on the diamond surface. The opposite inclination distributions of $\mathrm{Co}$ and $\mathrm{Cr}$ indicate the existence of a Co-based solid solution and the chemi-metallurgical combination is generated on the interface between the diamond abrasive surface and binder composites.

\section{Performance Analysis Of Gradient Cladding Layer}

\subsection{Microhardness}

The cross section microhardness of the gradient coating along the depth of the coatings is shown in Fig. 8. Across the depth of the cladding layer, the microhardness presents a decreasing trend. It is indicated that the coating can slow down the abrupt change of mechanical properties. The average hardness of the third layer, the second layer and the first layer stepwise decreased in corresponding order. The surface microhardness is the highest, and the microhardness value reaches $1342 \mathrm{HV}_{0.2}$. The microhardness of the interface between the substrate and the cladding layer is the lowest due to the larger grains being 
produced over a long period of thermal interaction. The microhardness of WC particles in the cladding layer is $2685 \mathrm{HV}_{0.2}$, and the mechanical properties of the cladding layer are enhanced by the dispersion of WC, diamond and other strengthening phases in the cladding layer.

\subsection{Wear resistance}

The comparison diagram of the friction coefficient and wear loss between the HSS substrate and composite gradient cladding layer is shown in Fig. 9. Before friction and wear testing, the frictional surfaces of each specimen were prepared with roughness values ranging from $0.13 \mu \mathrm{m}$ to 0.15 $\mu \mathrm{m}$. Variations on the friction coefficients within 30 minutes are presented in Fig. 9(a). One can conclude that the measured curves of the friction coefficients are characterized by the value of the oscillation of amplitude. As for the cladding layer, the friction curve fluctuates extremely in the initial stage. The mean value of the friction coefficient $\left(\mathrm{E}_{\mathrm{Cof}}\right)$ is approximately 0.27 . It can be also seen that the friction curve of the cladding layer fluctuates extremely at the initial stage due to protruded diamond particles leading to the fluctuation of the tangential force during the sliding test. As a feature of distinguishing the sliding stage, the curve of friction coefficient tending to be stable, as well as the appearance of smaller oscillations indicates that the transition from the initial stage to the stable stage begins to occur [29]. The sliding curves can be divided into different stages, as shown in Fig. 9(a) marked with the dash lines. Comparing with sliding the substrate, a longer wear initial stage was developed on sliding the cladding layer. It can be explained that the running-in time was prolonged owing to the superhard abrasive being distributed close to the top third layer. After stepping to the abrasion wear stage, the grinding ball began to contact with WC particles in addition to the diamond grains. The friction coefficient remains smooth and steady relatively due to the increase in the contact area between the ball and the cladding layer. In the breakage stage, part of the diamond grains were fractured and the broken particles were pushed into the contact area between the grinding ball and the worn surface of the layer along the sliding direction. The friction coefficient rose steeply. Subsequently, the sliding process steps into a stable stage with a slow increase of the friction coefficient. Three-body wear has been evoked due to the broken particles participating in the sliding process, which resulted in the fluctuation of the friction coefficient being risen.

One of the most glaring differences between the two curves is that the fluctuation of the friction coefficient in each stage(Fig. 9(a)). In the initial stage, the friction coefficient fluctuates widely owing to a poor surface quality similarity between grinding ball and sample. The higher surface quality similarity of the contact pairs will be produced as the sliding process develops. The friction coefficient tends to be stable. For the gradient cladding layer, there are significant variations in the material properties between layers. During the sliding process, not only would be the new texture of the coating ground, but the surface with the changed material arose at the contact area. And then it is difficult to form the high surface quality similarity between the ball and the ground surface. Therefore, a considerable oscillation of the friction coefficient is performed in four wear stages. The friction coefficients in sliding the two specimens become steady with the surface quality similarity of the pair increasing. A similar conclusion can be noted in the publication [30]. The larger $\mathrm{E}_{\mathrm{Cof}}$ and wear loss were tested in the ball sliding the HSS 
substrate (Fig. 9(b)). $\mathrm{E}_{\text {Cof }}$ of the cladding layer is 0.33 , and $\mathrm{E}_{\mathrm{Cof}}$ of the substrate is 0.56 . $\mathrm{E}_{\text {Cof }}$ of the cladding layer is decreased by twice as much as that of sliding the substrate. The wear loss of the cladding layer is $1.1 \mathrm{mg}$, and that of the substrate is $3.5 \mathrm{mg}$. The wear loss of the cladding layer is $1 / 3$ of that of HSS substrate. Compared with the HSS substrate, the newly prepared gradient cladding layer significantly improves the wear resistance of HSS.

In-depth understanding of wear resistance of the gradient cladding layer, the micro mechanism of improved wear resistance, the grinding mark on the friction and wear surface, as well as the interface between the abrasive and adhesive phase, was observed by the means of scanning electron microscopy (SEM), as shown in Fig. 10. The wear mechanism can be divided into adhesive wear, abrasive wear and fatigue wear according to the damage and failure modes of the friction surface. These various wear modes often occur simultaneously in one sliding test.

The distribution of hard particles, such as WC, diamond, and Co-based solid solution are dispersive and homogeneous in the high preparing wear-resistant coating layer. These hard particles are usually combined with the hard toughness adhesive phase in preparing the cladding layer. The hard particles protruding out from the surface can bear the load applied in the sliding test. The adhesive phase contributes to forming the compactness structure for the hard particles in the cladding layer, which is positive to absorb the energy and buffer the loads as the grinding ball slides over the surface of the composites. It is a reasonable origin for improving the comprehensive performance of the cladding layer $[31,32]$.

The micro-cutting furrow is obvious on the worn surface, as shown in Fig. 10(a). The micro-cutting furrow is consistent with the sliding direction of the counter-grinding ball. Due to the hardness of the ceramic ball being much higher than that of the cladding layer, the characteristic of the wrinkles generated on the surface of the adhesive phase along the wear scar indicates that the wear mode could be tagged with abrasive wear. Additionally, diamond particles are still embedded in the cladding surface despite a small amount being pulled out during the friction and wear process. A few microcracks could be discovered on the sliding track. Multi-layer laser cladding usually leads to geometric deformation in the superposition, while stress concentration is formed in the gradient layers. When the tensile stress close to the top layer exceeds the allowable stress, the microcrack propagation will be developed both in the cladding process and the sliding tests. Fig. 10(b) is an enlarged local view of the bottom of the wear marks. It can be noted that a little debris, as well as a few scabs, are sticking to the marks. It is indicated that adhesive wear was generated between the grinding ball and the cladding layer in the sliding test. On side of the wear mark (Fig. 10(c)), accumulation due to sliding plastic material can hardly be found on the side of the wear mark and a lot of plastic scratches were obviously observed in the adhesive alloy (Fig. 10(d)). It is implied that the hardness of the cladding material is much higher to cause little plastic formation.

The ingredient of debris close to the worn WC particle is marked in Fig. 10(e). It mainly includes the elements such as aluminum, oxygen, chromium, cobalt, and tungsten, as shown in Fig. 10(f). The element of aluminum contained in the debris indicates that the adhesive wear was generated in the 
sliding test. Also, a much higher content of oxygen detected on the wear surface implies that the oxidation wear mode occurs simultaneously. During the sliding test, the WC particles are difficult to be ground and the particles begin to emerge as the adhesive phase becomes worn out. The WC particles would bear the plow load coming from the grinding ball along the sliding direction and the micro material of the ball located in the contact area had been removed [33]. The removed material of the ball got buried in the worn surface and adhesive wear was produced. As well, a large amount of friction heat was induced during the sliding process. The brittle oxide film of the $\mathrm{Co}-\mathrm{Cr}$ alloy would be produced on the worn surface under the condition of exposure to air. Due to the diamond particles affording much of the sliding load, the edge of the particle was gradually ground to be dull and a little material around the particles had hardly been removed even if a few of the diamond grits were damaged (Fig. 10(g)). Micro spalling pits (Fig. 10(h)) observed on the diamond surface were formed arising from the brittleness removal according to the material removal mechanism [34]. A few diamond particles would be slightly damaged to a low strength status and turned to be brittleness after the laser cladding. Therefore, a small number of thermal cracks inevitably existed in diamond particles [35]. When the ball slides over the defect particles, the cracks will be propagated and diamond particles will be crushed to form the breakage (Fig. 10(i)).

The main wear modes induced in sliding the gradient cladding layer include abrasive wear, slight adhesive wear, and brittle peeling wear. The wear resistance of the gradient cladding layer is significantly improved due to the hard particles of the diamond and WC being embedded in the composites.

\subsection{Corrosion resistance}

Two specimens of the HSS substrate and the substrate with cladding layer were prepared for detecting the corrosion resistance. The corrosion kinetics are characterized by potentiodynamic polarization in $\mathrm{NaCl}$ solution with a molarity of $3.5 \%$ at a temperature of $25^{\circ} \mathrm{C}$ and the results are presented in Fig. 11. The corrosion potential of the gradient cladding layer is higher than that of the HSS substrate. Passivation can be monitored on both surfaces of two samples when the corrosion potential is ranged on a scale of -0.6 to $-0.4 \mathrm{~V}$. The electrochemical parameters were determined based on analyzing the Tafel curves and the results are listed in Table 5 . The corrosion potential $\left(E_{\text {corr }}\right)$, corrosion current density $\left(I_{\text {corr }}\right)$ and Tafel constant $\left(\beta_{\mathrm{a}}, \beta_{\mathrm{c}}\right)$ of anode/cathode were extracted by Tafel fitting method. The polarization resistance $\left(R_{\mathrm{p}}\right)$ can be calculated with the Stern-Geary equation [36]:

$$
R_{\mathrm{p}}=\frac{\beta_{\mathrm{a}} \beta_{\mathrm{c}}}{2.303 I_{\operatorname{corr}}\left(\beta_{\mathrm{a}}+\beta_{\mathrm{c}}\right)}
$$

According to the standpoint of corrosion kinetics, the corrosion rate is positively correlated with current density, while polarization resistance is inversely proportional to the current density. In general, the parameters of $E_{\text {corr }} I_{\text {corr }}$ and $R_{\mathrm{p}}$ are important for evaluating the corrosion characteristics of materials. Larger values of positive $E_{\text {corr }}$ and $R_{\mathrm{p}}$ together with the lower value of $I_{\text {corr }}$ will reflect an excellent 
corrosion resistance [37, 38]. Comparing the electrochemical data of the two samples, poor corrosion resistance can be predicted for the HSS substrate.

Table 5 Electrochemical data of substrate and coating

\begin{tabular}{|llllll|}
\hline Sample & $E_{\text {corr }}(\mathrm{V})$ & $I_{\text {corr }}\left(\mathrm{A} / \mathrm{cm}^{2}\right)$ & $\beta_{\mathrm{a}}(\mathrm{mv})$ & $\beta_{\mathrm{c}}(\mathrm{mv})$ & $R_{\mathrm{p}}\left(\Omega \cdot \mathrm{cm}^{2}\right)$ \\
\hline Substrate & -0.884 & $9.50 \mathrm{E}-05$ & 3.742 & 6.744 & 11003.5 \\
\hline Coating & -0.755 & $4.74 \mathrm{E}-06$ & 4.023 & 7.205 & 236488.1 \\
\hline
\end{tabular}

\section{Conclusions}

WC/diamond/Co-based gradient composite coatings were prepared on the surface of HSS substrates by laser cladding with different composition powder mixture. The phase composition, microstructural characterization, microhardness, wear resistance, as well as corrosion resistance of the gradient coatings, were investigated.

The following conclusions can be drawn.

(1) WC/diamond/Co-based gradient composite coatings were prepared on the HSS surface with a compacted structure morphology. The composites of the cladding layer are composed of $W C, M_{7} C_{3}(M$ is $\mathrm{Fe}, \mathrm{Cr}), \mathrm{Co}_{3} \mathrm{C}, \mathrm{W} 2 \mathrm{C}, \mathrm{CrCo}, \mathrm{Cr}_{3} \mathrm{C}_{2}, \mathrm{Co}, \mathrm{Fe}_{3} \mathrm{C}$, and $\mathrm{C}$.

(2) From the bottom layer to the top layer, the grain is gradually refined owing to the residual thermal interaction in the laser cladding. Element diffusions at the interface and chemical metallurgy combination between the particle (WC, diamond) and adhesive phase were realized. The wear resistance of the coating was improved due to the diamond and WC particles located on the cladding surface.

(3) In the friction and wear test, the friction coefficient values of the coatings range from 0.27 to 0.40 , which is much lower than that of the HSS substrate $(0.50-0.60)$. Due to the great different surface similarity between the ball and the cladding surface, a considerable oscillation of the friction coefficient is performed in four wear stages. The main wear modes that have been produced in sliding the gradient cladding layer include abrasive wear, slight adhesive wear, and brittle peeling wear.

(4) The microhardness of the cladding layer will increase as more content of WC being added to the mixture, and the surface hardness is the highest, reaching $1342 \mathrm{HV}_{0.2} . \mathrm{E}_{\mathrm{Cof}}$ is lower than that of the matrix, and the wear loss is only $1 / 3$ of that of the HSS substrate. The results show that the cladding layer has excellent corrosion resistance compared with the HSS matrix, and the $R_{\mathrm{P}}$ is $236488.1 \Omega \cdot \mathrm{cm}^{2}$.

\section{Declarations}


Authors' contributions Donggang Liu designed the experiments, finished the data analysis, and completed the paper writing. Professor Guoxing Liang provided the experimental program guidance and revised the draft. Xinhui Hao assisted with data acquisition and manuscript preparation. Yonggui Huang, Guang $\mathrm{Li}$ and Zheng Lv participated in the experiments and obtained the original experimental data. Professor Ming Lv guided the analysis of experimental data and finalized the manuscript, and provided good experimental conditions for the research. Mohammed Al-Nehari and Ojiako Tochukwu Princewill completed part of the experimental image processing and also carried on the final editing. All authors contributed and approved the final manuscript of this work.

Funding This research was funded by Natural Science Foundation of Shanxi Province of China (Grant No. 201801D121174) and Shanxi Provincial Key Research and Development Project of China (Grant No. 201903D121068).

Data availability The authors declare that the data and the materials of this study are available within the article. Raw data is also available from the authors upon a reasonable request.

Compliance with ethical standards

Ethical approval Not applicable.

Consent to participate Not applicable.

Consent to publish Not applicable.

Competing interests The authors declare that they have no known competing financial interests.

\section{References}

1. Rousseau AF, Partridge JG, Gözükara YM, Gulizia S, McCulloch DG (2016) Carbon evolution during vacuum heat treatment of high speed steel. Vacuum 124:85-88.

https://doi.org/10.1016/j.vacuum.2015.11.019

2. Liu ZG, Fu P, Zhao JZ, Ji F, Zhang YD, Nagaumi H, Wang XN, Zhao Y, Jia PF, Li WB (2020) Corrosion and high-temperature tribological behavior of carbon steel claddings by additive manufacturing technology. Surf Coat Technol 384:125325. https://doi.org/10.1016/j.surfcoat.2019.125325

3. Liu HX, Xu Q, Wang CQ, Zhang XW (2015) Corrosion and wear behavior of Ni60CuMoW coatings fabricated by combination of laser cladding and mechanical vibration. J Alloy Compd 621:357-363. https://doi.org/10.1016/j.jallcom.2014.10.030

4. Kivak T, Sarikaya M, Yildirim CV, Sirin S (2020) Study on turning performance of PVD TiN coated Al2O3 + TiCN ceramic tool under cutting fluid reinforced by nano-sized solid particles. J Manuf Process 56:522-539. https://doi.org/10.1016/j.jmapro.2020.05.017

5. Pakuła D, Staszuk M, Dziekońska M, Kožmín P, Čermák A (2018) Structure and properties of coating obtained by Chemical Vapour Deposition with the laser microstructuring. Vacuum 153:184-190. 
https://doi.org/10.1016/j.vacuum.2018.03.037

6. Zhao J, Gao QW, Wang HQ, Shu FY, Zhao HY, He WX, Yu ZS (2019) Microstructure and mechanical properties of Co-based alloy coatings fabricated by laser cladding and plasma arc spray welding. $J$ Alloy Compd 785:846-854. https://doi.org/10.1016/j.jallcom.2019.01.056

7. Yue TM, Xie H, Lin X, Yang HO, Meng GH (2014) Solidification behaviour in laser cladding of AlCoCrCuFeNi high-entropy alloy on magnesium substrates. J Alloy Compd 587:588-593. https://doi.org/10.1016/j.jallcom.2013.10.254

8. Huang FX, Jiang ZH, Liu XX, Lian JS, Chen L (2009) Microstructure and properties of thin wall by laser cladding forming. J Mater Process Technol 209(11):4970-4976. https://doi.org/10.1016/j.jmatprotec.2009.01.019

9. Weng F, Yu H, Chen C, Liu J, Zhao L (2015) Microstructures and properties of TiN reinforced Cobased composite coatings modified with $\mathrm{Y}_{2} \mathrm{O}_{3}$ by laser cladding on Ti-6Al-4V alloy. J Alloy Compd 650:178-184. http://dx.doi.org/10.1016/j.jallcom.2015.07.295

10. Fernández MR, García A, Cuetos JM, González R, Noriega A, Cadenas M (2015) Effect of actual WC content on the reciprocating wear of a laser cladding NiCrBSi alloy reinforced with WC. Wear 324325:80-89. https://doi.org/10.1016/j.wear.2014.12.021

11. Dubourg L, Ursescu D, Hlawka F, Cornet A (2005) Laser cladding of MMC coatings on aluminium substrate: influence of composition and microstructure on mechanical properties. Wear 258(1112):1745-1754. https://doi.org/10.1016/j.wear.2004.12.010

12. Rommel D, Scherm F, Kuttner C, Glatzel U (2016) Laser cladding of diamond tools: Interfacial reactions of diamond and molten metal. Surf Coat Technol 291:62-69. https://doi.org/10.1016/j.surfcoat.2016.02.014

13. Lian GF, Yao MP, Zhang Y, Huang X (2018) Analysis and respond surface methodology modeling on property and performance of two-dimensional gradient material laser cladding on die-cutting tool. Materials 11(10): 2052. https://doi.org/10.3390/ma11102052

14. Ma XX, Xiao B, Cao SH, Chen BH, Xu H (2018) A novel approach to fabricate w/cu functionally gradient materials. Int J Refract Met Hard Mat 72:183-193.

https://doi.org/10.1016/j.jirmhm.2017.11.021

15. Liang J, Yin XY, Lin ZY, Chen SY, Liu CS, Wang C (2020) Microstructure and wear behaviors of laser cladding in-situ synthetic $\left(\mathrm{TiB}_{\mathrm{x}}+\mathrm{TiC}\right) /\left(\mathrm{Ti}_{2} \mathrm{Ni}+\mathrm{TiNi}\right)$ gradient composite coatings. Vacuum 176:109305. https://doi.org/10.1016/j.vacuum.2020.109305

16. Liu FC, Mao YQ, Lin X, Zhou BS, Qian T (2016) Microstructure and high temperature oxidation resistance of Ti-Ni gradient coating on TA2 titanium alloy fabricated by laser cladding. Opt Laser Technol 83:140-147. https://doi.org/10.1016/j.optlastec.2016.04.005

17. Wang X, Zhang ZH, Men YZ, Li XJ, Liang YH, Ren LQ (2020) Fabrication of nano-TiC functional gradient wear-resistant composite coating on $40 \mathrm{Cr}$ gear steel using laser cladding under starved lubrication conditions. Opt Laser Technol 126:106136. https://doi.org/10.1016/j.optlastec.2020.106136 
18. Bartkowski D, Młynarczak A, Piasecki A, Dudziak B, Gos̈ciański M, Bartkowska A (2015) Microstructure, microhardness and corrosion resistance of Stellite- 6 coatings reinforced with WC particles using laser cladding. Opt Laser Technol 68:191-201. https://doi.org/10.1016/j.optlastec.2014.12.005

19. Bartkowski D, Matysiak W, Wojtko K (2018) Stellite-6 surface layers reinforced with hard and refractory WC particles produced on steel for metal forming. IOP Conf Series: Mater Sci Eng 393:012093. https://doi.org/10.1088/1757-899X/393/1/012093

20. Shi Y, Li YF, Liu J, Yuan ZY (2018) Investigation on the parameter optimization and performance of laser cladding a gradient composite coating by a mixed powder of Co50 and $\mathrm{Ni} / \mathrm{WC}$ on $20 \mathrm{CrMnTi}$ low carbon alloy steel. Opt Laser Technol 99:256-270. https://doi.org/10.1016/j.optlastec.2017.09.010

21. Riabkina-Fishman M, Rabkin E, Levin P, Frage N, Dariel MP, Weisheit A, Galun R, Mordike BL (2001) Laser produced functionally graded tungsten carbide coatings on M2 high-speed tool steel. Mater Sci Eng A 302(1):106-114. https://doi.org/10.1016/S0921-5093(00)01361-7

22. Fomin VM, Malikov AG, Orishich AM (2016) $\mathrm{CO}_{2}$ laser cladding heterogeneous ceramic-metal wearresistant coatings. AIP Conference Proceedings 1770: 020015. https://doi.org/10.1063/1.4963938

23. ASTM G5- (2011) 94(2011)e1, Standard Reference Test Method for Making Potentiostatic and Potentiodynamic Anodic Polarization Measurements. ASTM International, West Conshohocken.

24. Wang XY, Zhou SF, Dai XQ, Lei JB, Guo JB, Gu ZJ, Wang T (2017) Evaluation and mechanisms on heat damage of WC particles in Ni60/WC composite coatings by laser induction hybrid cladding. Int J Refract Met Hard Mat 64:234-241. https://doi.org/10.1016/j.ijrmhm.2016.11.001

25. Xu GJ, Kutsuna M, Liu ZJ, Sun LQ (2006) Characteristic behaviours of clad layer by a multi-layer laser cladding with powder mixture of Stellite- 6 and tungsten carbide. Surf Coat Technol 201(6):3385-3392. https://doi.org/10.1016/j.surfcoat.2006.07.210

26. Liu HX, Dong T, Zhang XW, Liu ZF, Shi H (2017) Microstructure and Cutting Performance of WC/Co50/Al Cemented Carbide Coated Tools Fabricated by Laser Cladding Process. Chin J Lasers 44(8):0802002. https://doi.org/10.3788/CJL201744.0802002 (In Chinese)

27. Tong X, Li FH, Kuang M, Ma WY, Chen XC, Liu M (2012) Effects of WC particle size on the wear resistance of laser surface alloyed medium carbon steel. Appl Surf Sci 258(7):3214-3220. https://doi.org/10.1016/j.apsusc.2011.11.066

28. Shen YJ, Li XF, Tang LP (2018) Effect of ultrasonic power on microstructure and properties of laserclad WC strengthened Fe-based composite coating. Heat Treat Met 43(5):168-172. https://doi.org/10.13251/j.issn.0254-6051.2018.05.033(In Chinese)

29. Liang GX, Schmauder S, Lv M, Schneider Y, Zhang C, Han Y (2018) An Investigation of the Influence of Initial Roughness on the Friction and Wear Behavior of Ground Surfaces. materials 11(2): 237. https://doi.org/10.3390/ma11020237

30. Menezes PL, Kishore Kailas SV (2008) Influence of roughness parameters on coefficient of friction under lubricated conditions. Sadhana 33:181-190. https://doi.org/10.1007/s12046-008-0011-8 
31. Gee MG, Gant A, Roebuck B (2007) Wear mechanisms in abrasion and erosion of WC/Co and related hardmetals. Wear 263(1-6):137-148. https://doi.org/10.1016/j.wear.2006.12.046

32. Bahoosh M, Shahverdi HR, Farnia A (2019) Abrasive Wear Behavior and Its Relation with the Macroindentation Fracture Toughness of an Fe-Based Super-Hard Hardfacing Deposit. Tribol Lett 67(3):100. https://doi.org/10.1007/s11249-019-1213-4

33. Cao J, Lu HF, Lu JZ, Luo KY (2019) Effects of tungsten carbide particles on microstructure and wear resistance of hot-working die prepared via laser cladding. Chin J Lasers 46(7):702001. https://doi.org/10.3788/CJL201946.0702001(In Chinese)

34. Jiang C, Cheng JY, Wu T (2017) Theoretical model of brittle material removal fraction related to surface roughness and subsurface damage depth of optical glass during precision grinding. Precis Eng 49:421-427. https://doi.org/10.1016/j.precisioneng.2017.04.004

35. Huang YG, Liang GX, Lv M, Li G, Liu DG (2020) Nd:YAG pulsed laser brazing of cBN to steel matrix with $\mathrm{Zr}$ modified $\mathrm{Ag}-\mathrm{Cu}-\mathrm{Ti}$ active brazing alloy. Diam Relat Mat 104:107732. https://doi.org/10.1016/j.diamond.2020.107732

36. Stern M, Geary AL (1957) Electrochemical Polarization: I. A Theoretical Analysis of the Shape of Polarization Curves. J Electrochem Soc 104(1):56-63. https://doi.org/10.1149/1.2428496

37. Wang QY, Pei R, Liu S, Wang SL, Dong LJ, Zhou LJ, Xi YC, Bai SL (2020) Microstructure and corrosion behavior of different clad zones in multi-track Ni-based laser-clad coating. Surf Coat Technol 402:126310. https://doi.org/10.1016/j.surfcoat.2020.126310

38. Zhang JQ, Lei JB, Gu ZJ, Tantai FL, Tian HF, Han JJ, Fang Y (2020) Effect of WC-12Co content on wear and electrochemical corrosion properties of Ni-Cu/WC-12Co composite coatings deposited by laser cladding. Surf Coat Technol 393:125807. https://doi.org/10.1016/j.surfcoat.2020.125807

\section{Figures}
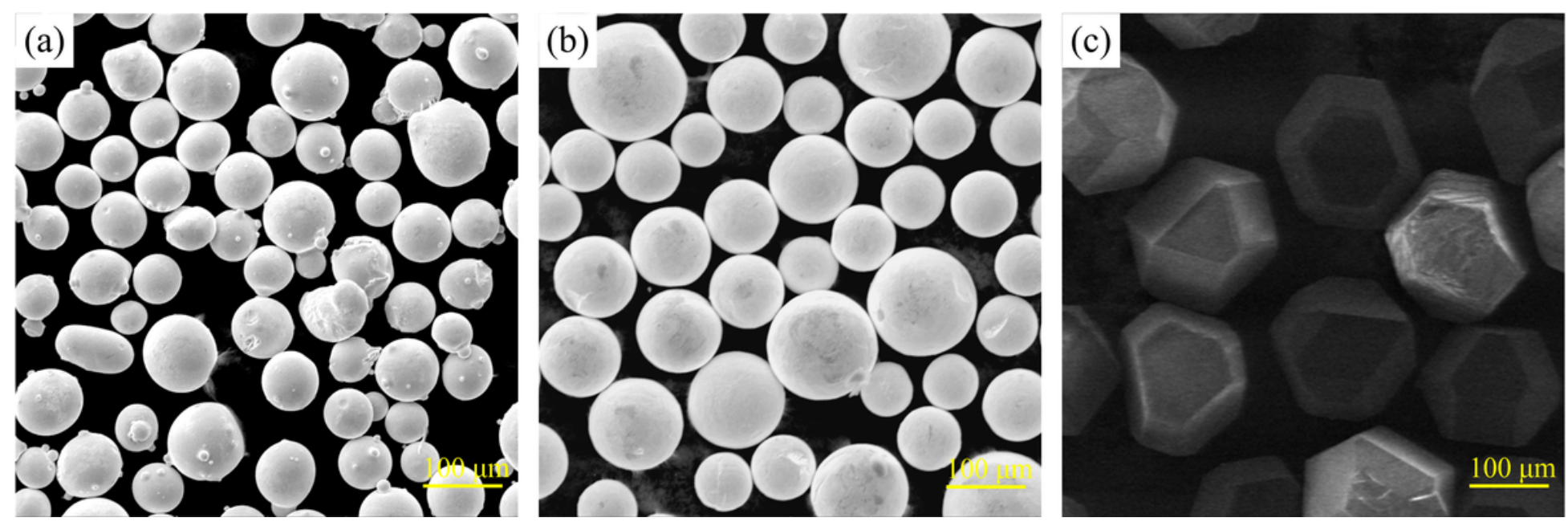

Figure 1

The micrograph of powders: a Co-Cr alloy. b WC. c Diamond abrasive 
Feed direction

$40 \% \mathrm{WC} / 7 \%$ diamond

$20 \% \mathrm{WC}$

Co-Cr alloy

Cladding layer

Substrate
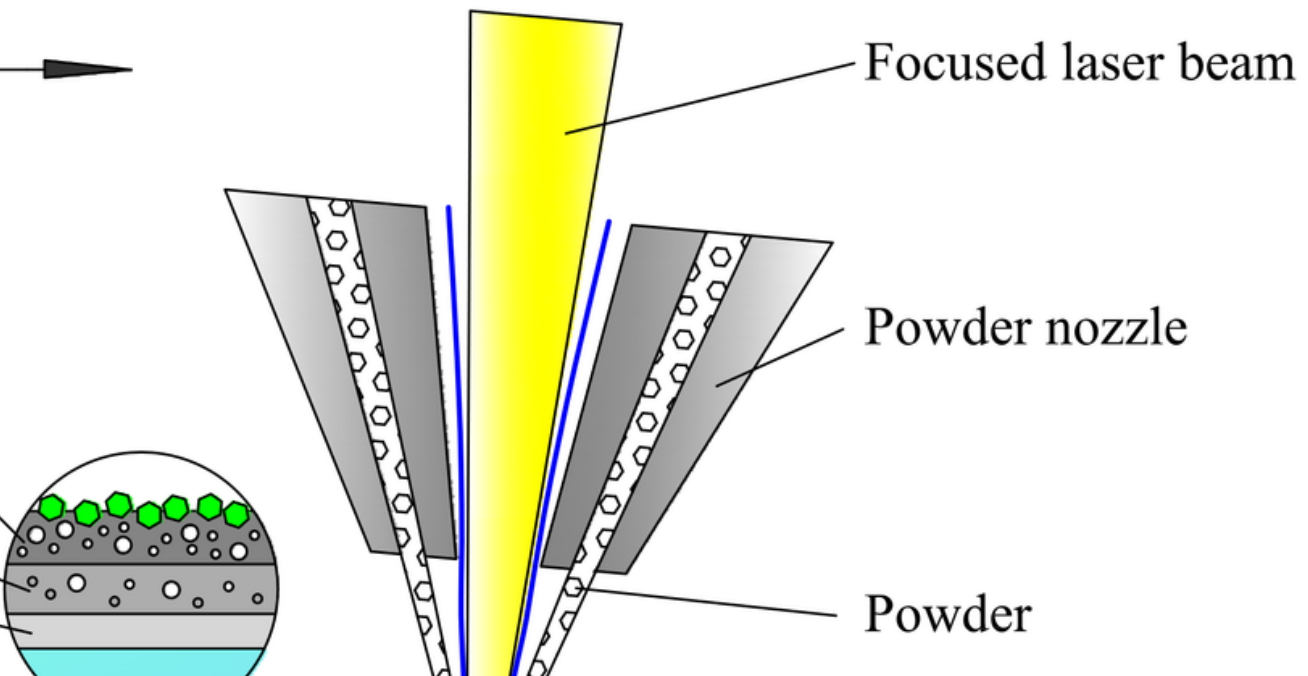

Work table

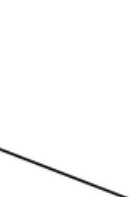

>
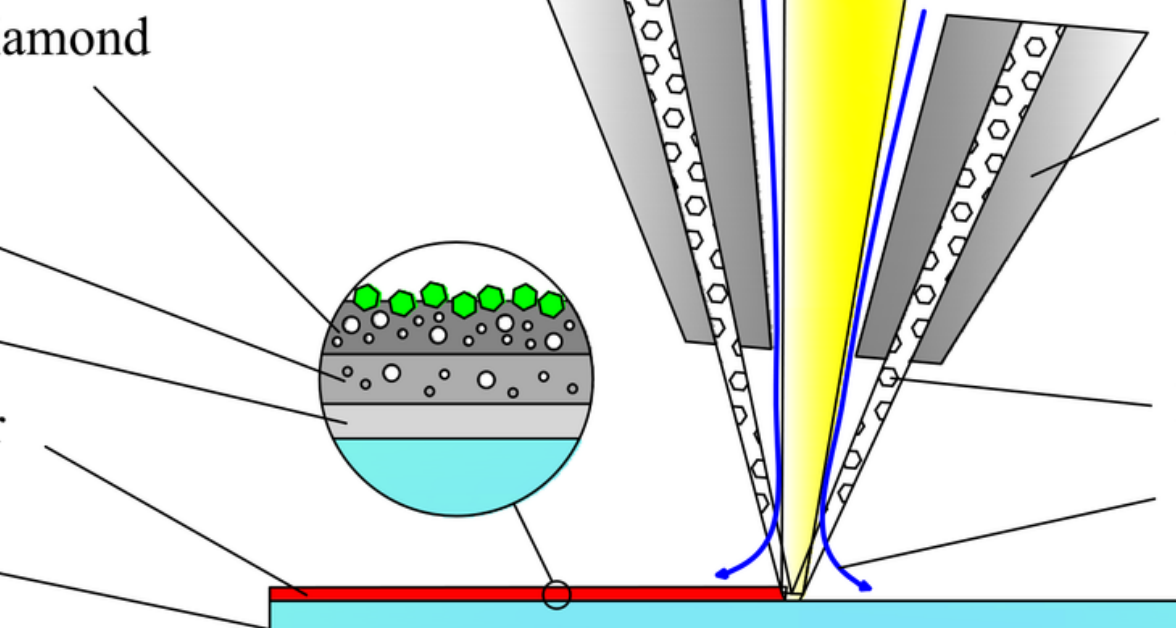

Powder nozzle

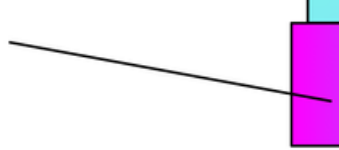

Figure 2

Schematic diagram of the laser cladding process
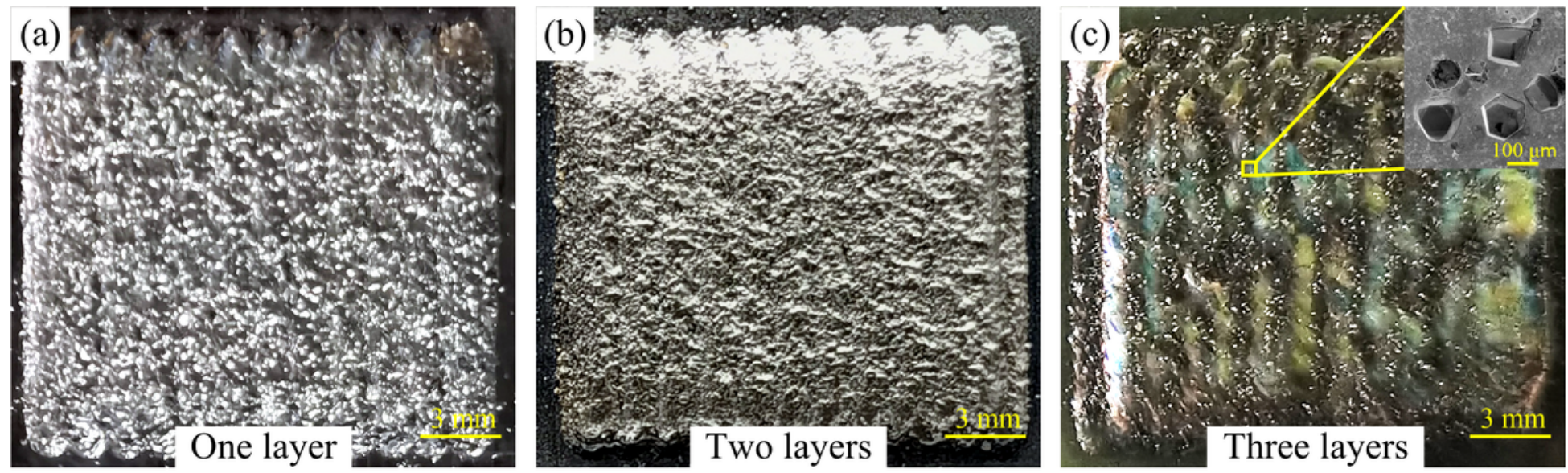

(d)

(e)

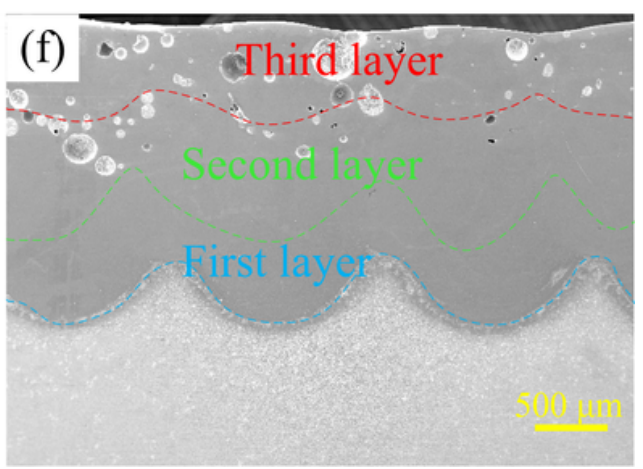

Figure 3 
The macroscopic morphology of gradient cladding layer: a Surface morphology of the one layer. b Surface morphology of the two layers. c Surface morphology of the three layers. $d$ Cross section of the one layer. e Cross section of the two layers. $f$ Cross section of the three layers
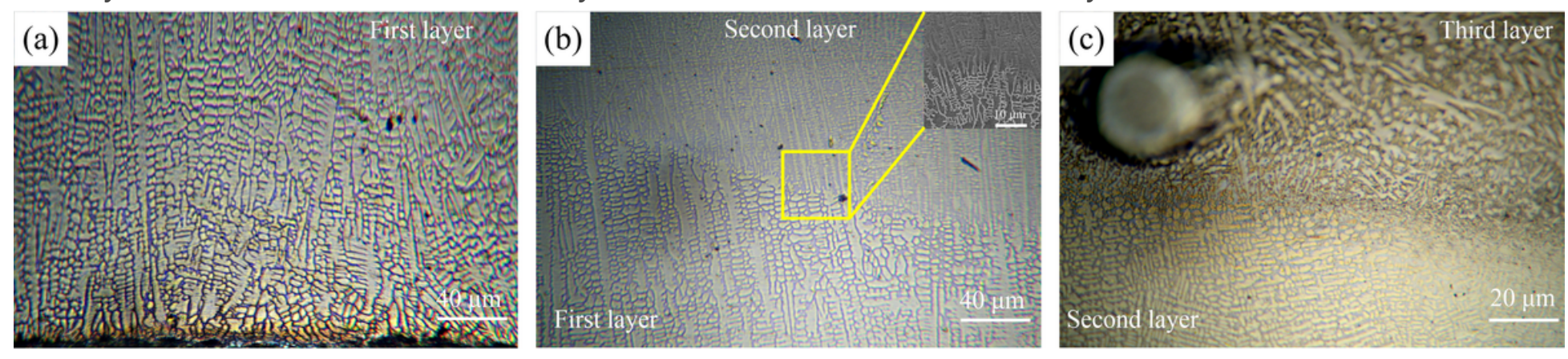

\section{Figure 4}

The interfacial metallographic structure of different gradient cladding layers: a First layer. b Second layer. c Third layer The microstructure of the bonding interface of each layer of the gradient cladding layer is shown in Fig. 4. Because the cladding layer contains multi-component, the phase composition of the composite coating does not present a single microstructure. In general, the microstructure at the bottom of the gradient cladding layer is more coarse than the cladding layer at the top. The microstructure of the cladding layer grows to a certain extent due to repeated heating. 


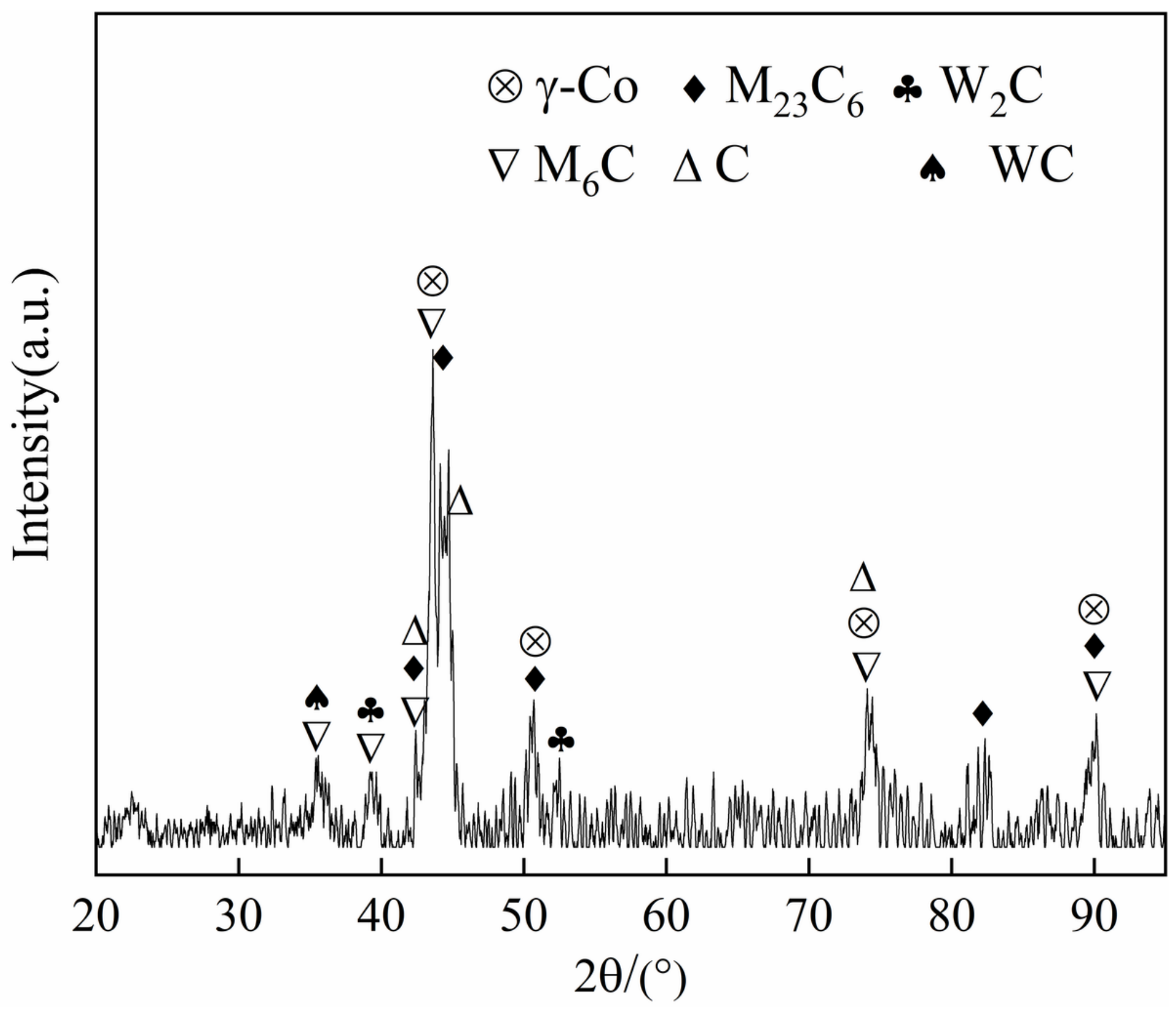

Figure 5

XRD pattern of the WC/diamond/Co-based coating. 

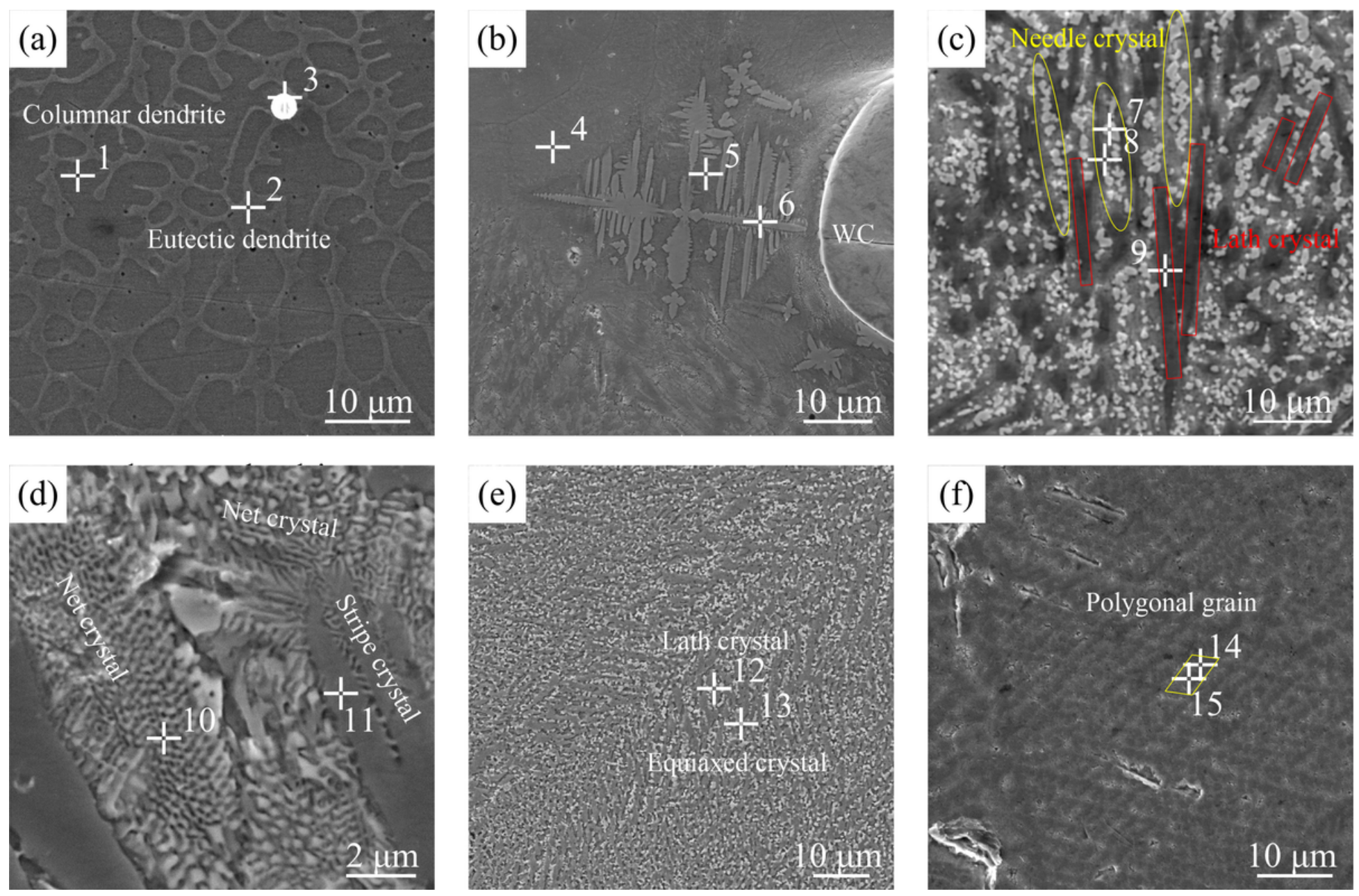

\section{Figure 6}

The sectional microstructure of gradient cladding layers: a First layer. b Dendrites near WC. c Acicular crystal of third layer. $d$ Net crystal of third layer. e Subsurface. $f$ Surface 

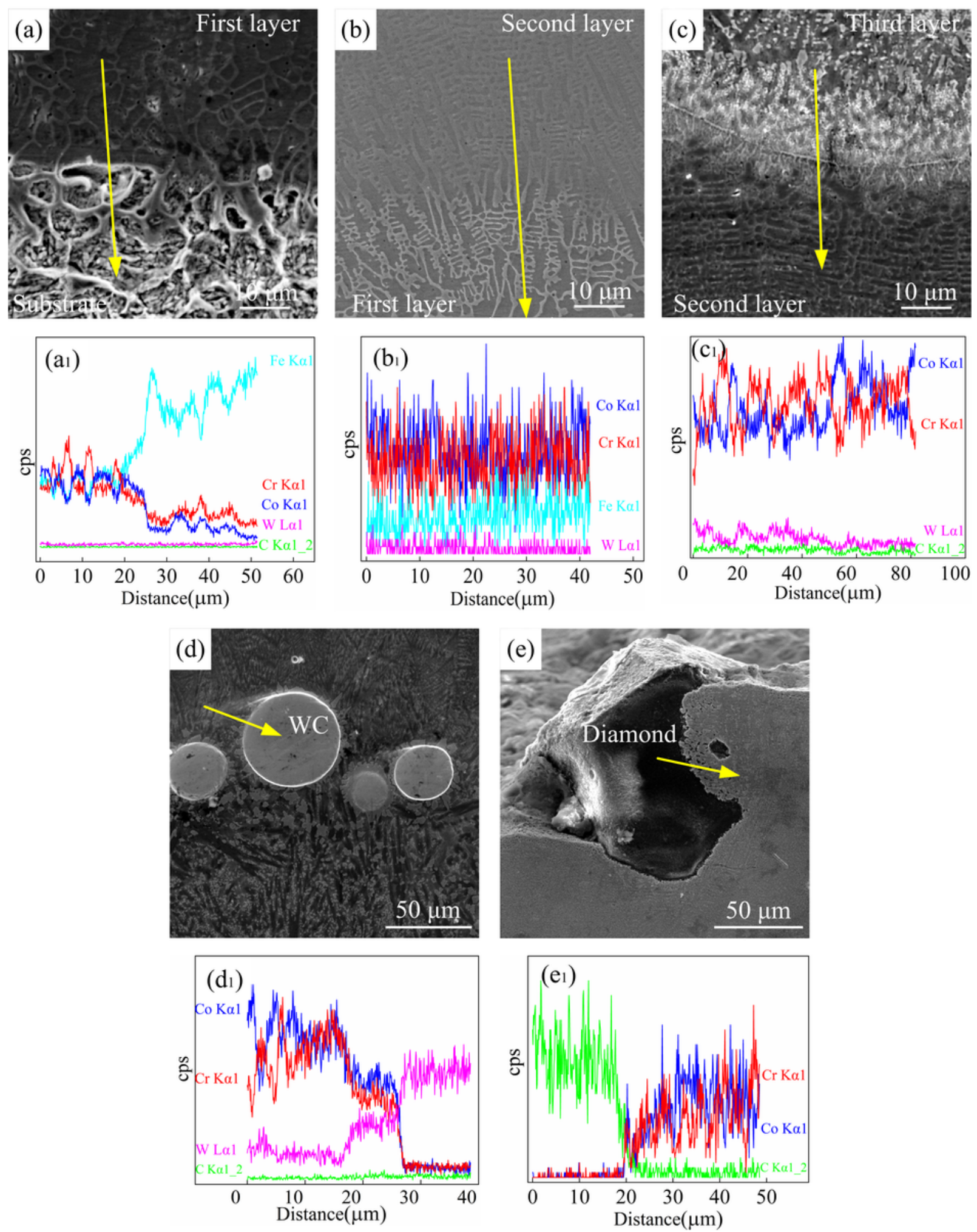

\section{Figure 7}

The interface microstructure of the gradient cladding layer and its main element distribution curves: a First layer and substrate. b Second layer and first layer. c Third layer and second layer. $\mathrm{d}$ WC and bonding phase. e Diamond and bonding phase 


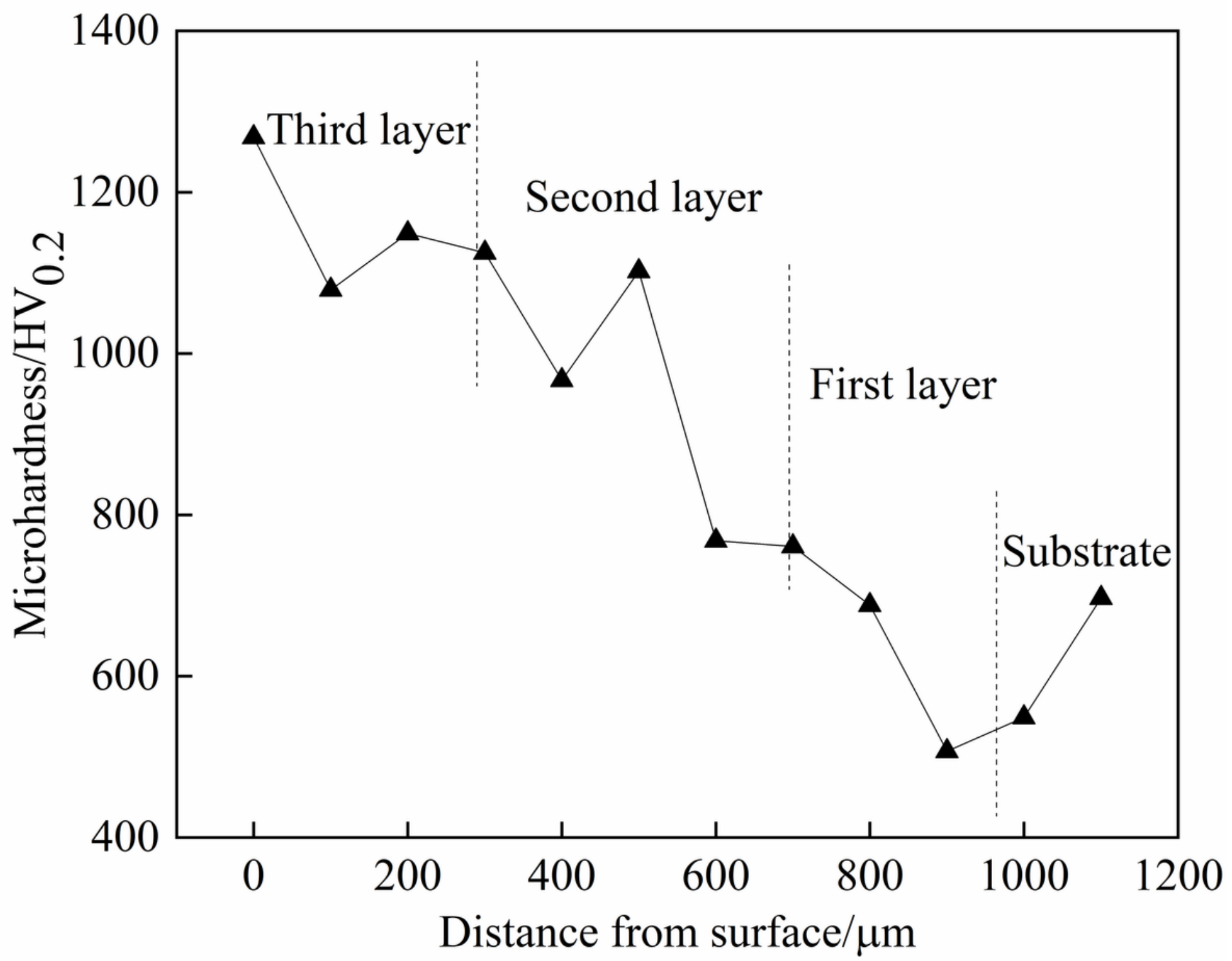

Figure 8

Microhardness distribution of gradient cladding layer
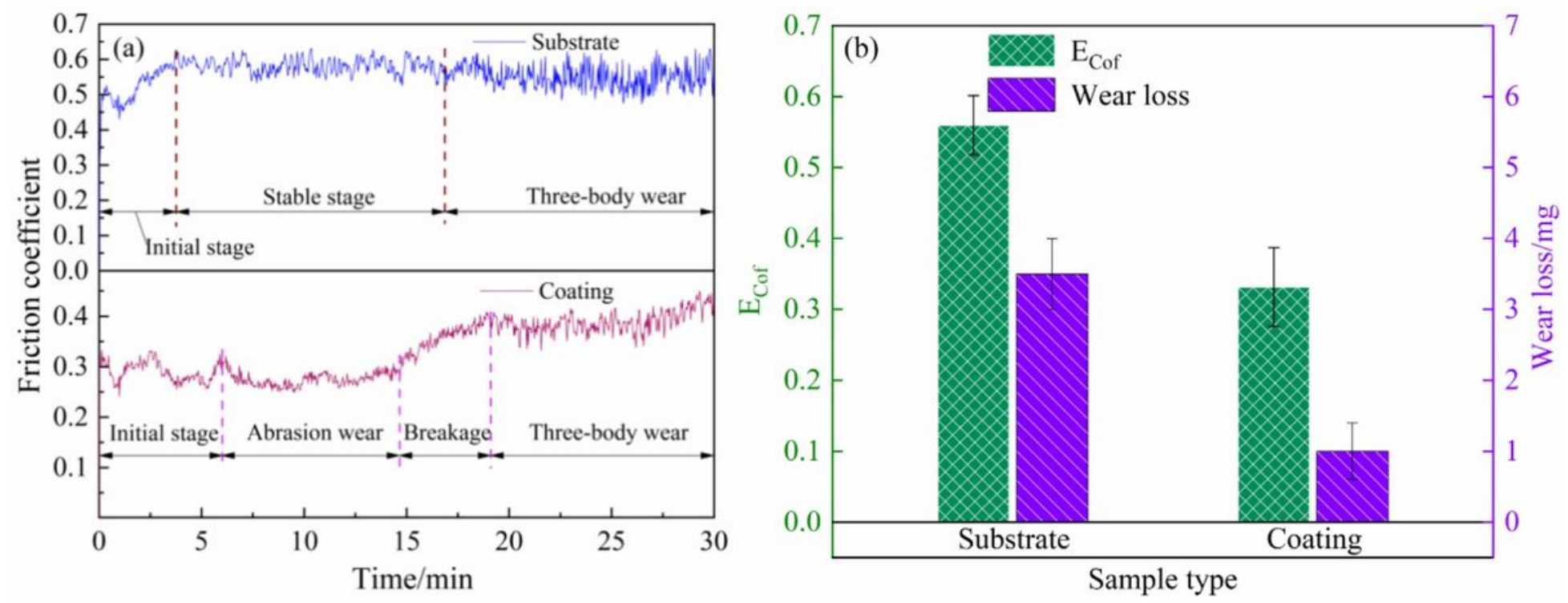
Figure 9

Date in the wear experiment: a Friction coefficient curves. b ECof and wear loss
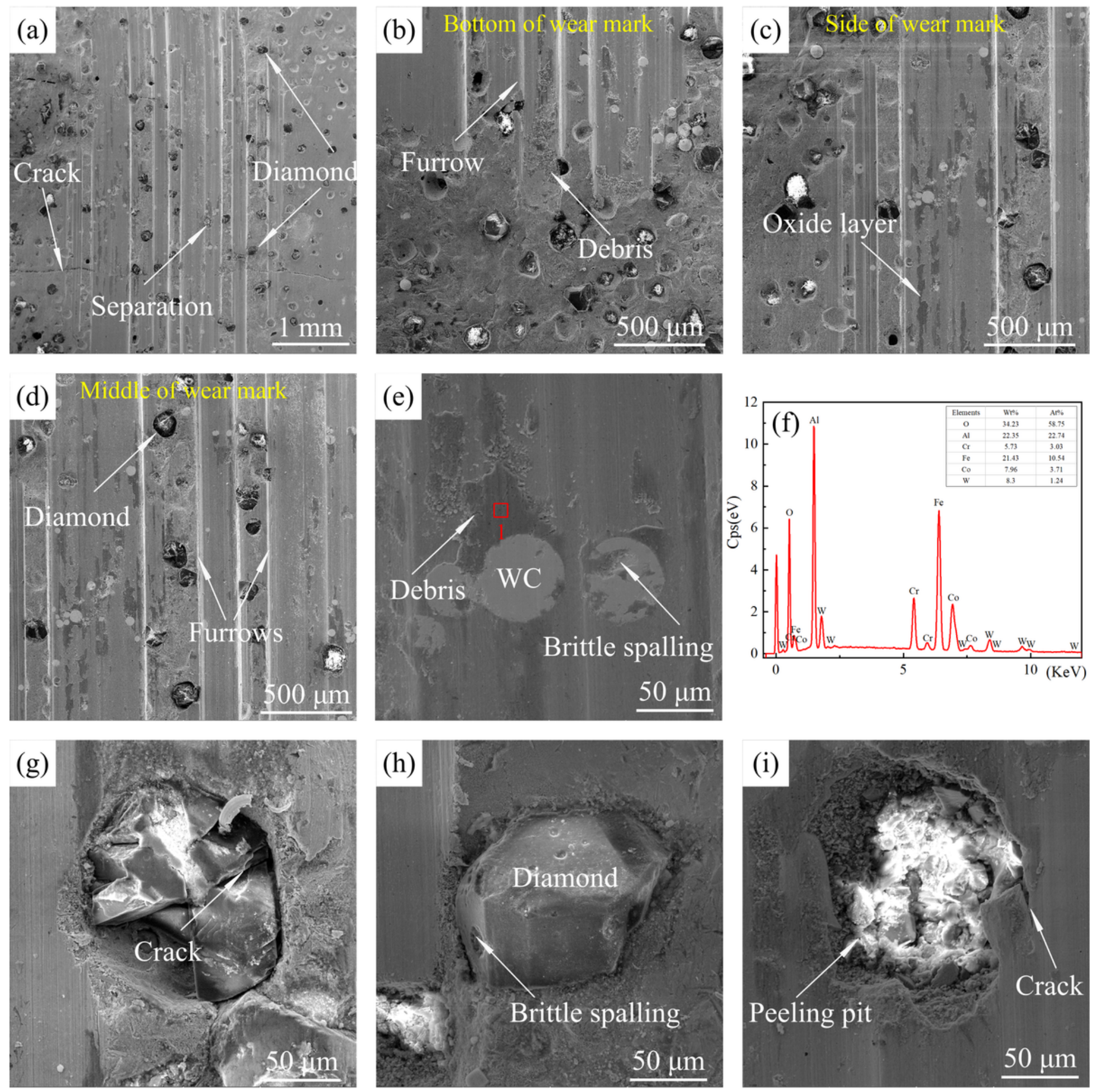

\section{Figure 10}

The worn surface of gradient cladding layer: a Integral wear mark. b Bottom of wear mark. c Side of wear mark. $d$ Middle of wear mark. e Wear WC. f EDS measurement results for zone 1. g Micro crack of the diamond. h Intact diamond. i Peeling pit 


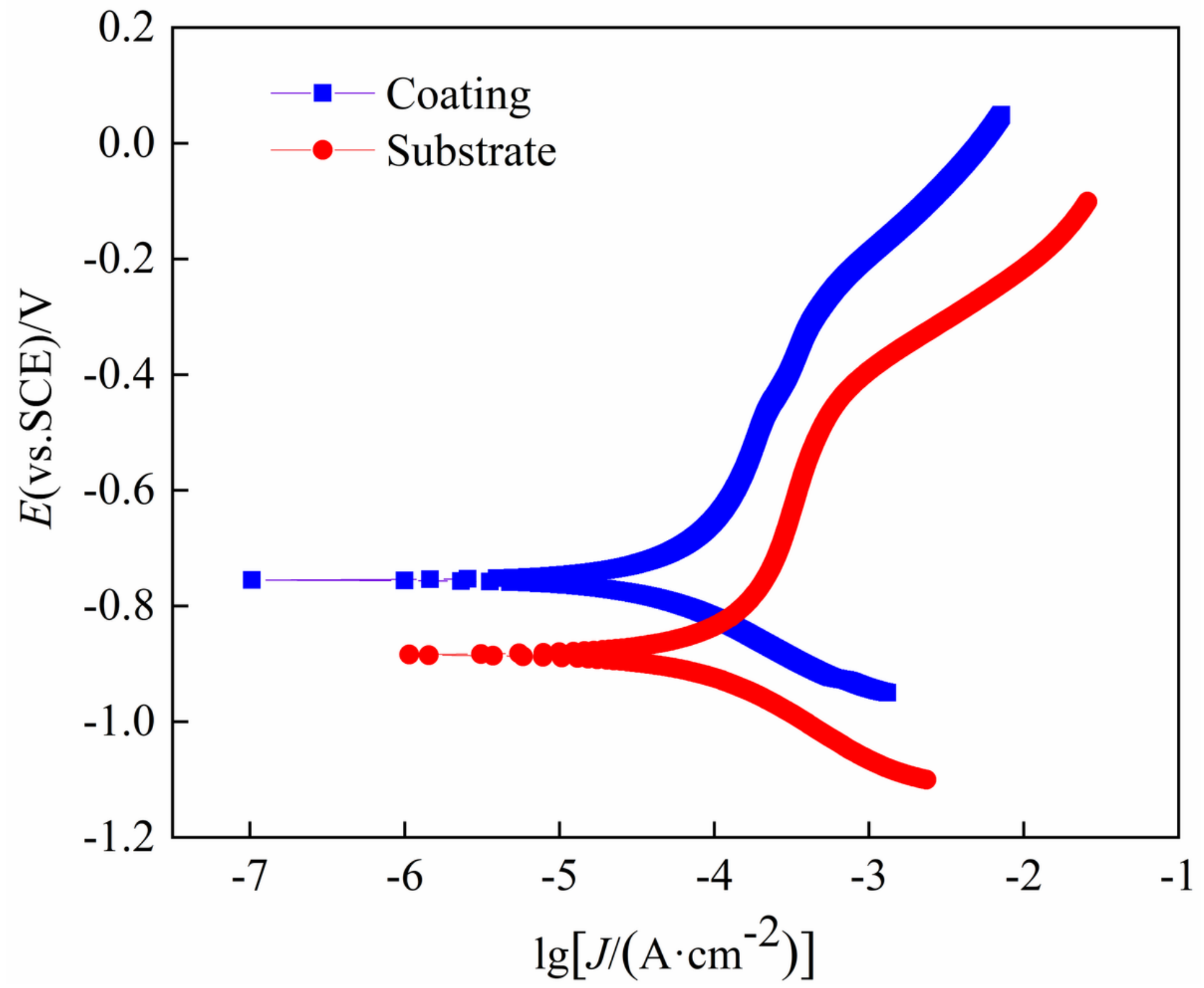

Figure 11

Potentiodynamic polarization of HSS substrate and coating.

\section{Supplementary Files}

This is a list of supplementary files associated with this preprint. Click to download.

- Fig.1.vsd

- Fig.10.vsd

- Fig.11.opju

- Fig.3.vsd

- Fig.4.vsd 
- Fig.5.opju

- Fig.6.vsd

- Fig.7.vsd

- Fig.8.opju

- Fig.9a.opju

- Fig.9b.opju 